\section{Cardiomyopathy Caused by Longterm Treatment with Chloroquine: A Rare Disease, or a Rare Diagnosis?}

\section{To the Editor:}

Chloroquine (CQ) has been used for the treatment and prophylaxis of malaria since World War II. Ten years later, the administration of CQ and hydroxychloroquine (HCQ) was introduced for the longterm therapy of rheumatic diseases. Although no reliable statistical data are available, HCQ, which differs from CQ only in a hydroxyl group at the end of the side chain, but not in pharmacokinetics or metabolism, is described in the literature as less toxic and has been staging a comeback, particularly in the treatment of systemic lupus erythematosus (SLE) ${ }^{1}$.

CQ and HCQ induce a dysfunction of the lysosomal enzymes, leading to the impairment of intracellular degradation processes in conjunction with the accumulation of pathological metabolic products (glycogen and phospholipids). These appear histologically as granulovacuolar cell mutations and ultrastructurally as lamellar inclusion bodies ("myeloid bodies") and as "curvilinear bodies" in cytoplasm (remnants of poorly digested membranes) $)^{2,3}$. Their pharmacokinetics are characterized by a long half-life and a high volume of distribution; they follow a multicompartment model with very slow distribution between plasma and tissue, leading to sustained organ sequestration and sometimes irreversible organ damage ${ }^{4}$

Severe toxicity in the form of irreversible retinopathy ${ }^{5}$ is well known under longterm treatment with these substances. In contrast, neuromyopathy ${ }^{6}$ and especially cardiac damage ${ }^{7}$ receive scant mention in the literature. Cardiac complications comprise conduction disturbances [bundle-branch block, atrioventricular (AV) block] and cardiomyopathy - often with hypertrophy, restrictive physiology, and congestive heart failure (literature reviews are found in Nord, et $a l^{8}$ and Costedoat-Chalumeau, et $a l^{9}$ ).

Because the clinical features of cardiotoxicity are unspecific, the followup of potentially affected patients is of utmost importance.

We report a case of a patient with rheumatoid arthritis (RA) and heart disease who was treated with CQ.

A 65-year-old woman was admitted for rehabilitation after having undergone surgery for lumbar spinal stenosis in April 2007. Electrocardiography revealed an atypical bundle-branch block. She reported mild dyspnea and angina pectoris (New York Heart Association Class II) for many years without progression. A diagnosis of hypertensive heart disease was rendered in 2001. In October 2006 she experienced syncope with subsequent resuscitation. The electrocardiogram showed a complete AV block, and a dual-chamber pacemaker was implanted. There were no indications of myocarditis or variation in her medications preceding the syncope. CQ medication was continued; she recovered completely.

Her history revealed that she had been diagnosed with RA 43 years before. It was treated with corticosteroids, nonsteroidal antiinflammatory drugs, and CQ. Azathioprine, methotrexate, gold compounds, and leflunomide were discontinued because of side effects. CQ had been administered for 35 years ( $250 \mathrm{mg}$ daily), and the cumulative dose was $3195 \mathrm{~g} \mathrm{CQ}$ phosphate. Except for a slow, continuous deterioration of her vision, she noted no other side effects.

Her medications upon admission included CQ phosphate $250 \mathrm{mg}$, naproxen $500 \mathrm{mg}$ (twice daily), prednisolone $15 \mathrm{mg}$, oxycodone $40 \mathrm{mg}$, nebivolol $2.5 \mathrm{mg}$, torsemide $10 \mathrm{mg}$, and pantoprazole $40 \mathrm{mg}$.

On examination she appeared to be in good general condition, with blood pressure $140 / 80 \mathrm{~mm} \mathrm{Hg}$ and heart rate $84 / \mathrm{min}$. Mild synovitis of the finger joints and severe polyarthropathic deformities due to longstanding RA were noted. There was no evidence of muscular weakness, no impairment of sensation, and no diminished stretch reflexes. Heart and lungs were without pathological findings. There was no distension of the jugular veins, no edema, and vascular status was normal.

Laboratory findings showed elevation of enzyme levels (lactate dehydrogenase $426 \mathrm{U} / 1$, reference -247; creatine kinase $259 \mathrm{U} / 1$, ref. -145; creatine kinase-MB/mass $11.7 \mu \mathrm{g} / 1$, ref. -3.6 ; troponin I $0.26 \mathrm{ng} / \mathrm{ml}$, ref. -0.1) and rheumatoid factor $(160 \mathrm{IU} / \mathrm{ml}$, ref. -15$)$. The remaining laboratory results were normal.

Under Holter monitoring no arrhythmia was detected; regular function of the pacemaker was noted. Transthoracic echocardiography showed normal-size atria and ventricles, borderline hypertrophy $(1.2 \mathrm{~cm})$, hypokinesis of the posterior and lateral wall, mitral insufficiency $\mathrm{I}-\mathrm{II}^{\circ}$, diastolic dysfunction $\mathrm{II}^{\circ}$, and no signs of restrictive physiology.

Chest radiography found the ventricular pacemaker lead in the coronary sinus, while the heart and lungs were normal. Magnetic resonance imaging (MRI) revealed left ventricular (LV) hypertrophy (lateral wall 1.9 $\mathrm{cm})$ and LV ejection fraction 53\%, caused by hypokinesis of the apical anterior and the basal inferolateral wall. The delayed gadolinium enhancement sequence (Figure 1) showed decreased viability in a nonvascular pattern, but no myocardial edema to suggest myocarditis.

Left heart catheterization revealed a LV end-diastolic pressure of 10 $\mathrm{mm} \mathrm{Hg}$; no coronary artery disease was found. Five endomyocardial biopsies were obtained from the lateral wall, guided by the delayed enhancement pattern in MR imaging.

Pathological examination (Figure 2) showed extensive cytoplasmic
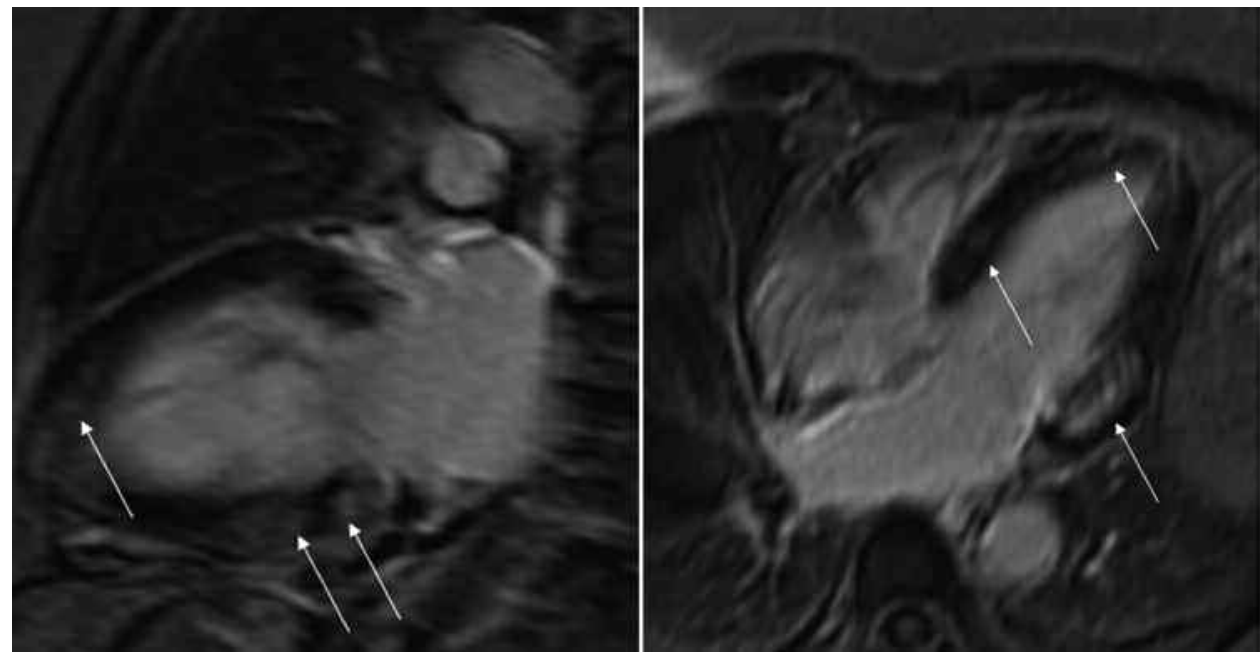

Figure 1. Magnetic resonance imaging shows decreased viability of the left ventricle in a nonvascular pattern (arrows indicate delayed gadolinium enhancement). Left panel: modified 2-chamber view; right panel: 4-chamber view. 


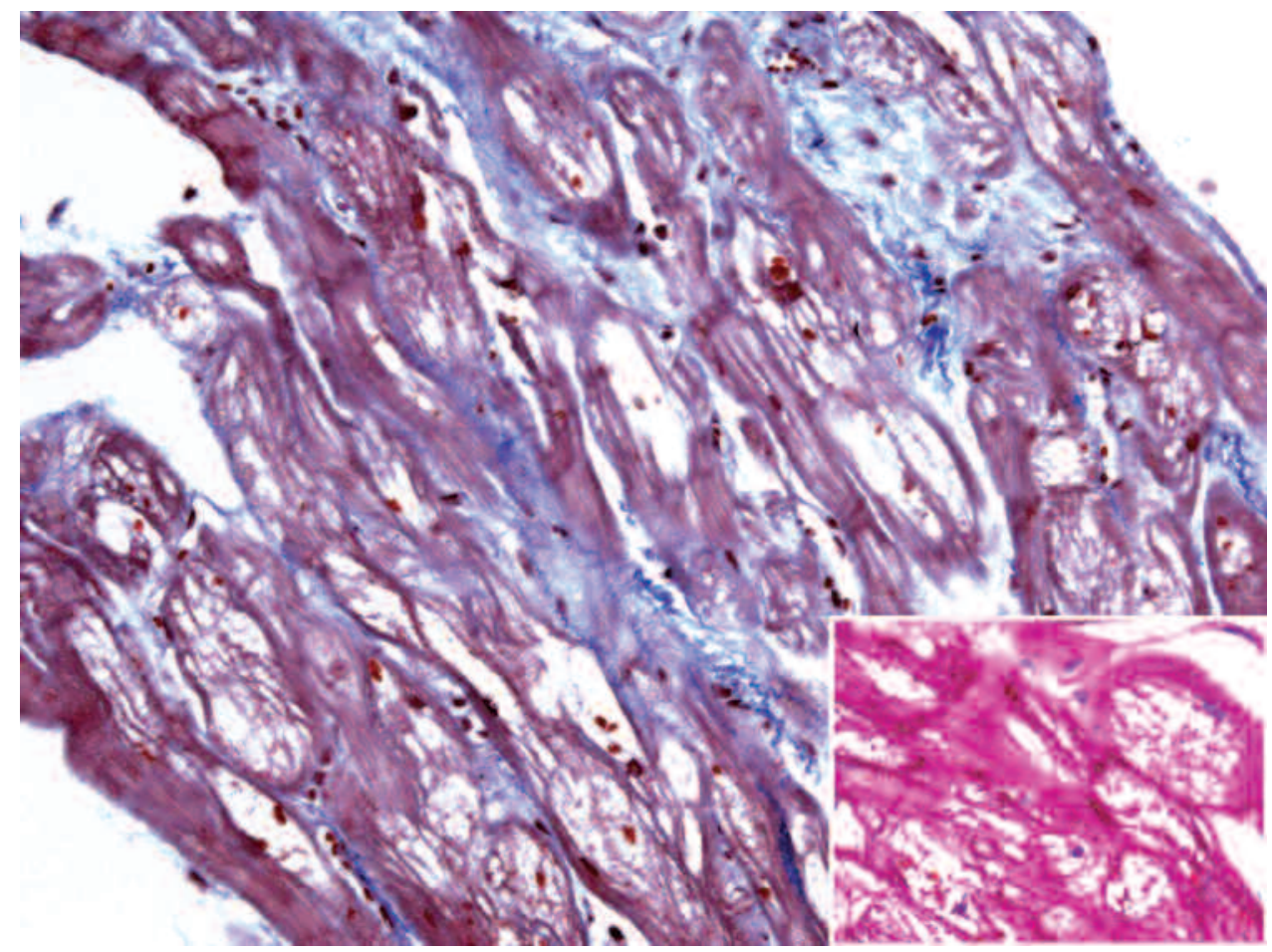

Figure 2. Endomyocardial biopsy from the left ventricle. Light microscopy (Masson's trichrome staining) shows marked cytoplasmic vacuolization of the myocytes with periodic acid-Schiff-positive granular deposits (insert).
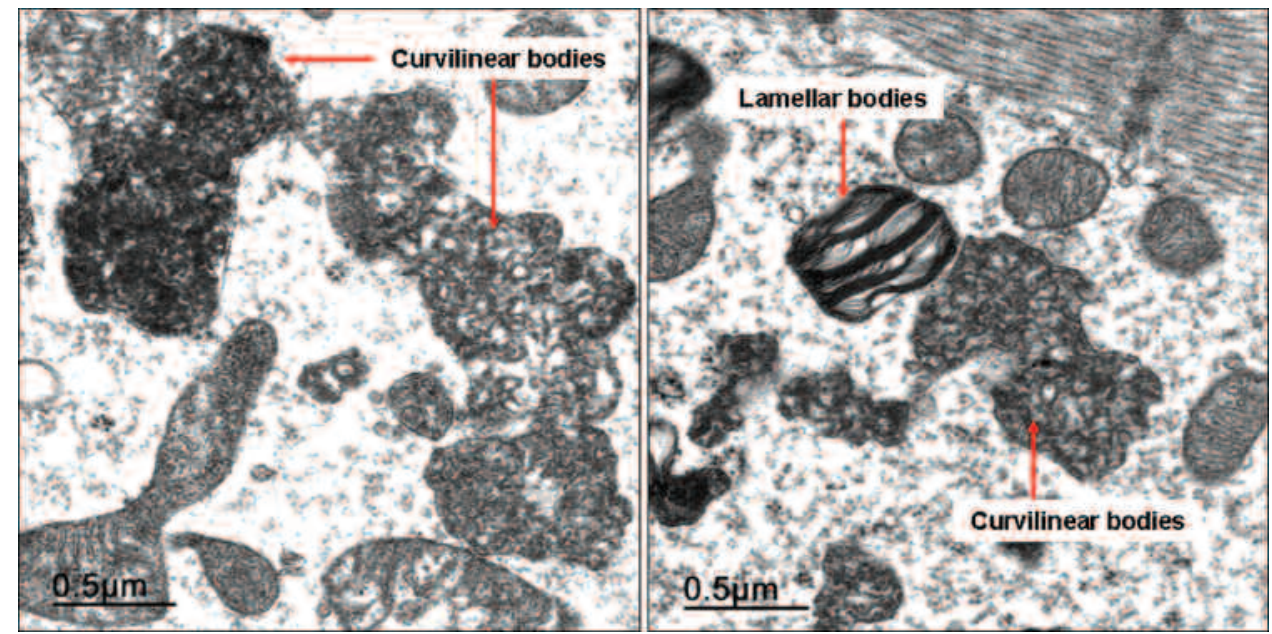

Figure 3. Endomyocardial biopsy from the left ventricle. Transmission electron microscopy shows lamellar and curvilinear cytoplasmic inclusion bodies in the myocytes.

vacuolization of the myocytes, mild interstitial fibrosis, no evidence of inflammation or vasculitis (including immunohistology), no amyloid deposition, and no cell necrosis. Transmission electron microscopy (Figure 3) revealed accumulation of numerous lamellar and curvilinear inclusion bodies in the myocytes. Molecular pathology (nested polymerase chain reaction) disclosed no infections of the myocardium with enteroviruses, adenoviruses, parvovirus B19, human herpesvirus 6, Epstein-Barr virus, or Borrelia burgdorferi.

The diagnosis of Fabry disease was excluded by molecular genetic testing. The serum CQ level was $0.27 \mathrm{mg} / 1$, which is in the therapeutic range. Ophthalmologic examination revealed signs of chronic CQ intoxication (bull's-eye maculopathy of the left eye).
CQ medication was discontinued. Followup 14 months later showed persistence of the complete AV block. The serum enzyme levels had decreased slightly. From a clinical point of view, there was no indication of congestive heart failure, but there was progression of retinopathy and visual loss.

As seen in our case, there are no clinical signs that indicate unambiguously that cardiotoxicity was induced by CQ. Further, there is no correlation between the different organ toxicities (cardiomyopathy, retinopathy, neuromyopathy), which would permit analogous diagnostic conclusions, and the determination of blood levels is not accurate for detecting CQ toxicity (serum level was in the therapeutic range), due to the complex pharmacokinetics and the large interindividual fluctuation range in the metabo-

Personal non-commercial use only. The Journal of Rheumatology Copyright @ 2012 . All rights reserved. 
Table 1. Details of chloroquine/hydroxychloroquine-induced cardiomyopathies (case reports including histologic studies of the myocardium).

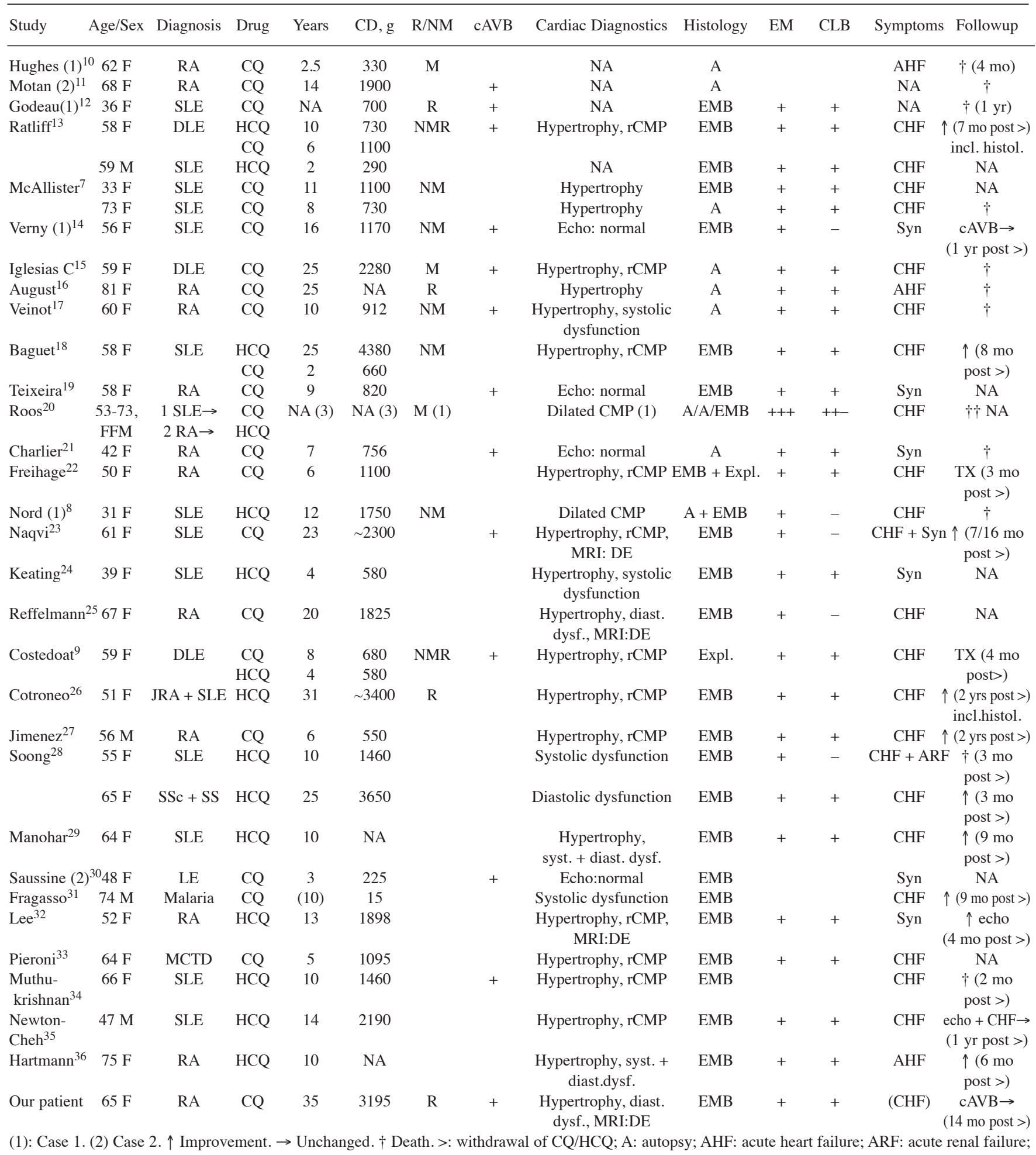

cAVB: complete AV block; CD: cumulative dose; CHF: congestive heart failure; CLB: curvilinear bodies; CMP: cardiomyopathy; CQ: chloroquine; DE: delayed enhancement; diast.: diastolic; DLE: discoid lupus erythematosus; dysf.: dysfunction; echo: echocardiography; EM: electron microscopy; EMB: endomyocardial biopsy; Expl.: explanted heart; HCQ: hydroxychloroquine; histol.: histology; MCTD: mixed connective tissue disease; MRI: magnetic resonance imaging; NA: not available; NM: neuromyopathy; R: retinopathy; (J)RA: (juvenile) rheumatoid arthritis; rCMP: restrictive cardiomyopathy; SSc: systemic sclerosis; (S)LE: (systemic) lupus erythematosus; SS: Sjögren's syndrome; Syn: syncope; syst.: systolic; TX: heart transplant.

Personal non-commercial use only. The Journal of Rheumatology Copyright $\subset$ 2012. All rights reserved. 
lism of the substance ${ }^{4}$. Thus, the cardiac process may be asymptomatic for a long period.

Because of the small number of cases and the lack of systematic studies, it is impossible to calculate the incidence of CQ cardiotoxicity; however, a considerable number of undetected cases can be assumed. To date, reports have been published on 35 patients with biopsy-proven cardiomyopathy $7,8,9,10,11,12,13,14,15,16,17,18,19,20,21,22,23,24,25,26,27,28,29,30,31,32,33,34,35,36$ and on 30 patients with total AV block only $9,30,37,38$. Moreover, 12 of those patients with cardiomyopathy exhibited complete AV block as well (Table 1). Most patients were treated with CQ, but in recent years there has been a clear trend toward HCQ. All except one of them (who had recurrent malaria) had connective tissue diseases (predominantly RA and SLE).

The cumulative dose of CQ/HCQ (15-5040 g) and the duration of treatment (2-31 years) vary greatly. Our patient had the longest duration of treatment (35 years) and one of the highest cumulative doses (3195 g).

To date, it has not been possible to establish predictive values for any of the measures, such as age, sex, duration of treatment, cumulative dose, or underlying illness, in order to estimate toxicity in individual cases.

Cardiac complications include conduction disturbances and cardiomyopathy. As in our patient, several cases have been described in the literature in which complete $\mathrm{AV}$ block precedes the cardiomyopathy and the medication continues to be administered because of improper evaluation of the pathogenesis ${ }^{9,15,23}$. We could not determine other causes for the AV block, and there is no known accumulation of higher-grade AV conduction disorders in conjunction with $\mathrm{RA}^{39}$. Recently, the case of a patient with sick sinus syndrome as a result of CQ therapy was also reported ${ }^{32}$.

The cardiomyopathy is predominantly of the restrictive type (with diastolic dysfunction), but mainly systolic impairment has also been reported (Table 1). The most common pathological result in cardiac imaging is myocardial hypertrophy. Congestive heart failure is the prevailing clinical symptom. However, some patients have very few, discrete symptoms, or none at all (as in our case, in which we found no indication of restrictive kinetics, either).

In view of the large number of variables in the clinical hypothesis, the histological examination plays an extremely important role. As a rule, the morphology of the tissue damage caused by $\mathrm{CQ} / \mathrm{HCQ}$ is identical in all organs involved. Light microscopic study reveals a vacuolar myopathy. Ultrastructurally, lamellar and so-called "curvilinear" inclusion bodies can be demonstrated. The curvilinear bodies are comma-shaped structures which in human pathology occur only in cases of CQ damage and in neuronal ceroid lipofuscinosis, a group of hereditary neurodegenerative disorders in children $7,8,40$.

While curvilinear bodies definitively document the pathogenesis of CQ toxicity, the presence of lamellar inclusion bodies is also described after the administration of amiodarone and in other storage diseases ${ }^{41}$ (Table 2). In

Table 2. Differential diagnoses of chloroquine/hydroxychloroquine cardiomyopathy.

Connective tissue diseases

Varia

Storage diseases

Inflammation
Systemic lupus erythematosus

Rheumatoid arthritis

Dermatomyositis

Polymyositis

Steroid myopathy

Other causes for conduction disturbances

Hypertensive heart disease

Hypertrophic cardiomyopathy sui generis

Fabry disease

Niemann-Pick disease

Amiodarone-induced cardiomyopathy

Other lysosomal storage diseases

Amyloidosis

Viral myocarditis

Lupus myocarditis

Vasculitis particular, Fabry disease, which is also accompanied by myocardial hypertrophy, can make the differential diagnosis difficult ${ }^{20,28}$.

The range of differential diagnoses in the case of vacuolar myopathy revealed under light microscopy is considerably larger and includes the connective tissue diseases and steroid myopathy ${ }^{2,3}$ (Table 2). Because rheumatic diseases often involve the cardiovascular system, and cortisone preparations are frequently prescribed, overlaps can occur and the symptoms of toxic damage are often ascribed to the underlying rheumatic disease and its complications.

To avoid the sampling error of blind biopsies (because of a patchy distribution of the pathological process in the myocardium) we took MR-guided biopsies from the left ventricle, following the delayed enhancement pattern in MRI ${ }^{42}$. Both the vacuolar myopathy (Figure 2) as well as the curvilinear bodies (Figure 3 ) were unequivocally documented in the myocardial specimen, so that the diagnosis of CQ cardiotoxicity was definitive. Further, the following diseases were excluded by means of differential diagnosis and testing: coronary artery disease, myocarditis and vasculitis (because of the underlying rheumatic disease), viral myocarditis, amyloidosis, steroid myopathy, and Fabry disease.

Based on strict histological (ultrastructural) criteria, the diagnosis of $\mathrm{CQ} / \mathrm{HCQ}$-induced cardiomyopathy has been confirmed pathologically in only 24 patients to date (Table 1 ).

The prognosis for patients with this cardiomyopathy appears to be mixed: heart transplants had to be performed in 2 patients with refractory heart failure ${ }^{9,22}$. Thirteen patients died (most of them soon after the diagnosis was established). The course of the illness was not clear for 8 patients, and an improvement was described in only 10 cases (Table 1).

It must be noted that cardiotoxicity is difficult to diagnose under longterm treatment with $\mathrm{CQ} / \mathrm{HCQ}$ and is presumably often overlooked in everyday clinical practice. Early detection is of utmost importance, as no therapy is available, the reversibility of organ damage is questionable, and severe courses of illness have been described. In case of longterm treatment and high cumulative doses, we propose at least annual followup examinations (including electrocardiography). If myocardial damage is suspected, further diagnostic measures including ultrastructural examination of myocardial tissue are required.

\section{ACKNOWLEDGMENT}

The authors thank Dr. M. Farr (Department of Cardiology, Heart and Diabetes Center NRW, Ruhr University of Bochum, Bad Oeynhausen, Germany) for conducting the molecular genetic testing for Fabry disease.

ERNST TÖNNESMANN, MD; INGO STROEHMANN, MD, Department of Internal Medicine, Kaiser-Karl-Klinik, Bonn; REINHARD KANDOLF, MD, PhD; HARTWIG WOLBURG, PhD, Institute for Pathology and Neuropathology, University of Tübingen; KATHARINA STRACH, MD, Department of Radiology, University of Bonn; FRANK MUSSHOFF, PhD, Institute of Forensic Medicine, University of Bonn; KLAUS TIEMANN, MD; THORSTEN LEWALTER, MD, Department of Cardiology, University of Bonn, Germany. Dr. Stroehmann is deceased. Address correspondence to Dr. E. Tönnesmann, Kaiser-Karl-Klinik, Graurheindorfer Str. 137, D-53117 Bonn, Germany.

E-mail: e.toennesmann@t-online.de

\section{REFERENCES}

1. Costedoat-Chalumeau N, Leroux G, Amoura Z, Piette JC. Hydroxychloroquine dans le traitement du lupus: le renouveau. Rev Méd Interne 2008;29:735-7.

2. Gérard JM, Stoupel N, Collier A, Flament-Durand J. Morphologic study of a neuromyopathy caused by prolonged chloroquine treatment. Eur Neurol 1973;9:363-79.

3. Rewcastle NB, Humphrey JG. Vacuolar myopathy: clinical, histochemical, and microscopic study. Arch Neurol 1965;12:570-82.

4. Tett SE. Clinical pharmacokinetics of slow-acting antirheumatic 
drugs. Clin Pharmacokinet 1993;25:392-407.

5. Marmor MF, Carr RE, Easterbrook M, Farjo AA, Mieler WF. Recommendations on screening for chloroquine and hydroxychloroquine retinopathy (a report by the American Academy of Ophthalmology). Ophthalmology 2002;109:1377-82.

6. Stein M, Bell MJ, Ang LC. Hydroxychloroquine neuromyotoxicity. J Rheumatol 2000;27:2927-31.

7. McAllister HA Jr, Ferrans VJ, Hall RJ, Strickman NE, Bossart MI Chloroquine-induced cardiomyopathy. Arch Pathol Lab Med 1987;111:953-6.

8. Nord JE, Shah PK, Rinaldi RZ, Weisman MH. Hydroxychloroquine cardiotoxicity in systemic lupus erythematosus: A report of 2 cases and review of the literature. Semin Arthritis Rheum 2004;33:336-51.

9. Costedoat-Chalumeau N, Hulot JS, Amoura Z, Delcourt A, Maisonobe T, Dorent R, et al. Cardiomyopathy related to antimalarial therapy with illustrative case report. Cardiology 2007; 107:73-80.

10. Hughes JT, Esiri M, Oxbury JM, Whitty CW. Chloroquine myopathy. Q J Med 1971;40:85-93.

11. Motan J, Topinka I, Dura J, Kvapilova H. Chlorochinova kardiodystrofie [Chloroquine cardiodystrophy]. Vnitr Lek 1978;24:1122-8.

12. Godeau P, Guillevin L, Fechner J, Bletry O, Herreman G. Les troubles de conduction au cours du lupus érythémateux: fréquence et incidence dans une population de 112 patients. Ann Méd Interne 1981;132:234-40

13. Ratliff NB, Estes ML, Myles JL, Shirey EK, McMahon JT. Diagnosis of chloroquine cardiomyopathy by endomyocardial biopsy. N Engl J Med 1987;316:191-3.

14. Verny C, de Gennes C, Sébastien P, Huong Du LT, Chapelon C, Piette JC, et al. Troubles de la conduction cardiaque au cours d'un traitement prolongé par chloroquine - Deux nouvelles observations. Press Méd 1992;21:800-4.

15. Iglesias Cubero G, Rodriguez Reguero JJ, Rojo Ortega JM. Restrictive cardiomyopathy caused by chloroquine. Br Heart J 1993;69:451-2

16. August C, Holzhausen HJ, Schmoldt A, Pompecki R, Schröder S. Histological and ultrastructural findings in chloroquine-induced cardiomyopathy. J Mol Med 1995;73:73-7.

17. Veinot JP, Mai KT, Zarychanski R. Chloroquine related cardiac toxicity. J Rheumatol 1998;25:1221-5.

18. Baguet JP, Tremel F, Fabre M. Chloroquine cardiomyopathy with conduction disorders. Heart 1999;81:221-3.

19. Teixeira RA, Martinelli Filho M, Benvenuti LA, Costa R, Pedrosa AA, Nishióka SA. Cardiac damage from chronic use of chloroquine: A case report and review of the literature. Arq Bras Cardiol 2002;79:85-8.

20. Roos JM, Aubry MC, Edwards WD. Chloroquine cardiotoxicity: Clinicopathologic features in three patients and comparison with three patients with Fabry disease. Cardiovasc Pathol 2002;11:277-83.

21. Charlier P, Cochand-Priollet B, Polivka M, Goldgran-Tolédano D, Leenhardt A. Cardiomyopathie à la chloroquine révélée par un bloc auriculo-ventriculaire complet [Chloroquine cardiomyopathy revealed by complete AV block. A case report]. Arch Mal Coeur Vaiss 2002;95:833-7.

22. Freihage JH, Patel NC, Jacobs WR, Picken M, Fresco R, Malinowska K, et al. Heart transplantation in a patient with chloroquine-induced cardiomyopathy. J Heart Lung Transplant 2004;23:252-5.

23. Naqvi TZ, Luthringer D, Marchevsky A, Saouf R, Gul K, Buchbinder NA. Chloroquine-induced cardiomyopathy echocardiographic features. J Am Soc Echocardiogr 2005;18:384-8.

24. Keating RJ, Bhatia S, Amin S, Williams A, Sinak LJ, Edwards WD. Hydroxychloroquine-induced cardiotoxicity in a 39-year-old woman with systemic lupus erythematosus and systolic dysfunction. J Am Soc Echocardiogr 2005;18:981. e1-5.

25. Reffelmann T, Naami A, Spuentrup E, Kühl HP. Contrast-enhanced magnetic resonance imaging of a patient with chloroquine-induced cardiomyopathy confirmed by endomyocardial biopsy. Circulation 2006;114:357-8.

26. Cotroneo J, Sleik KM, Rene Rodriguez E, Klein AL. Hydroxychloroquine-induced restrictive cardiomyopathy. Eur J Echocardiogr 2007;8:247-51.

27. Hernández Jiménez V, Saavedra Falero J, Navas R. Miocardiopatia restrictiva reversible secundaria a cloroquina (Cartas al editor) [Myocardiopathy secondary to chloroquine - letter]. Med Clin (Barc) 2007;129:157.

28. Soong TR, Barouch LA, Champion HC, Wigley FM, Halushka MK. New clinical and ultrastructural findings in hydroxychloroquine-induced cardiomyopathy - A report of 2 cases. Hum Pathol 2007;38:1858-63.

29. Manohar VA, Moder KG, Edwards WD, Klarich KW. Restrictive cardiomyopathy secondary to hydroxychloroquine therapy. J Rheumatol 2009;36:440-1.

30. Saussine A, Loriot M-A, Picard C, Lecerf V, Landry J, Scheer I, et al. Cardiotoxicité après un traitement au long cours par chloroquine chez deux patientes lupiques. Ann Dermatol Venereol 2009;136:530-5.

31. Fragasso G, Sanvito F, Baratto F, Martinenghi S, Doglioni C, Margonato A. Cardiotoxicity after low-dose chloroquine antimalarial therapy. Heart Vessels 2009;24:385-7.

32. Lee JH, Chung WB, Kang JH, Kim HW, Kim JJ, Kim JH, et al. A case of chloroquine-induced cardiomyopathy that presented as sick sinus syndrome. Korean Circ J 2010;40:604-8.

33. Pieroni M, Smaldone C, Camporeale A, Ierardi C, Dell'Antonio G, Bellocci F, et al. Chloroquine-induced transition from dilated to restrictive cardiomyopathy (Images in cardiology). J Am Coll Cardiol 2011;57:515.

34. Muthukrishnan P, Roukoz H, Grafton G, Jessurun J, Colvin-Adams M. Hydroxychloroquine-induced cardiomyopathy: A case report. Circ Heart Fail 2011;4:e7-8.

35. Newton-Cheh C, Lin AE, Baggish AL, Wang H. A 47-year-old man with systemic lupus erythematosus and heart failure (Case 11-2011). N Engl J Med 2011;364:1450-60.

36. Hartmann M, Meek IL, van Houwelingen GK, Lambregts HPCM, Toes GJ, van der Wal AC, et al. Acute left ventricular failure in a patient with hydroxychloroquine-induced cardiomyopathy. Neth Heart J 2011;19:482-5.

37. El aichaoui S, Amine B, Saoud B, Guedira N, Allali F, Hajjaj-Hassouni N. Bloc auriculoventriculaire complet au cours d'un traitement par chloroquine [Complete auriculoventricular block during chloroquine treatment]. Rev Méd Interne 2007;28:134-6

38. Puymirat E, Douard H, Roudaut R. Bloc auriculo-ventriculaire complet après prise de chloroquine au long cours [Complete auriculoventricular block after long-term chloroquine treatment]. Rev Méd Interne 2008;29:741-3.

39. Jurik AG, Moller P. Atrioventricular conduction time in rheumatoid arthritis. Rheumatol Int 1985;5:205-7.

40. Boldrini R, Biselli R, Santorelli FM, Bosmann C. Neuronal ceroid lipofuscinosis: An ultrastructural, genetic, and clinical study report. Ultrastruct Pathol 2001;25:51-8.

41. Tegnér R, Tomé FMS, Godeau P, Lhermitte F, Fardeau M. Morphological study of peripheral nerve changes induced by chloroquine treatment. Acta Neuropathol 1988;75:253-60.

42. Mahrholdt H, Goedecke C, Wagner A, Meinhardt G, Athanasiadis A, Vogelsberg H, et al. Cardiovascular magnetic resonance assessment of human myocarditis: A comparison to histology and molecular pathology. Circulation 2004;109:1250-8.

J Rheumatol 2012;39;5; doi:10.3899/jrheum.110959

Personal non-commercial use only. The Journal of Rheumatology Copyright $\odot$ 2012. All rights reserved. 


\section{Correction}

\section{Cardiomyopathy Caused by Longterm Treatment with Chloroquine: A Rare Disease or a Rare Diagnosis?}

E. Tönnesmann, I. Stroehmann, R. Kandolf, H.Wolburg, K. Strach, F. Musshoff, K. Tiemann, T. Lewalter.

Cardiomyopathy caused by longterm treatment with chloroquine: A rare disease or a rare diagnosis? J Rheumatol 2012;39:1099-1104. In Table 1 of the online version of this report, for the authors Roos, Freihage, and Nord, listed in Column 1, the entries intended for Column 10 under "Histology" are misaligned. The entries should read: "A/A/EMB" for Roos, "EMB" for Friehage, and "A" for Nord. The author listing in Column 1 "Jimenez" should read "Hernandez-Jimenez". A corrected pdf of this report is available from the online table of contents. To view/download the corrected version visit jrheum.org and follow the prompts to Volume 39, No. 5.

doi:10.3899/jrheum.110959.C1 